\title{
Pedagogía popular a partir de prácticas artísticas marginales realizadas con objetos de lo cotidiano*
}

POPULAR PEDAGOGY FROM MARGINAL ARTISTIC PRACTICES

MADE WITH EVERYDAY OBJECTS

PEDAGOGIA POPULAR A PARTIR DE PRÁTICAS ARTÍSTICAS MARGINAIS

REALIZADAS COM OBJETOS DO COTIDIANO

\section{Dimo Leonardo, García Camargo**}

Cuadernos de Música, Artes Visuales y Artes Escénicas

/Volumen 12 - Número 2 / Julio - Diciembre de 2017

/ ISSN 1794-6670/ Bogotá, D.C., Colombia / pp. 125-145

Fecha de recepción: 31 de enero de 2017

Fecha de aceptación: 5 de junio de 2017

Disponible en línea: 29 de agosto de 2017

doi:10.11144/javeriana.mavae12-2.pppp

* Artículo de investigación.

* Maestro en Artes plásticas por la Universidad Nacional de Colombia, máster en Artes Visuales por la Université de Strasbourg II, doctor en Artes visuales por Faculté des Arts, Université de Strasbourg. Profesor de la Universidad Pedagógica Nacional de Colombia. 


\section{Resumen}

Este artículo examina algunas prácticas artísticas marginales que pueden entenderse como generadoras de un enriquecimiento disidente y de un bienestar social divergente frente a

las lógicas economicistas que imperan en el mundo contemporáneo. Asimismo, estudia algunas características del arte marginal (outsider art) realizado con objetos de lo cotidiano, con el fin de elaborar algunas orientaciones metodológicas,

a partir de dichas características, para una pedagogía popular que permita un trabajo de exploración artística y de emancipación social.

Palabras claves:arte marginal; educación popular; objetos de lo cotidiano; experimentación; emancipación; riqueza

\section{Abstract}

This text examines some marginal artistic practices, which can be understood as generating dissenting enrichment and divergent social welfare in the face of the economicist logic that prevails in the contemporary world. In this article we are going to study some characteristics of the marginal art (outsider art) realized with everyday objects, in order to elaborate some methodological orientations, from those characteristics, for a popular pedagogy that allows a work of artistic exploration and of Social emancipation.

Keywords: marginal art; popular education; everyday objects experimentation; emancipation; wealth

\section{Resumo}

Este texto examina algumas práticas artísticas consideradas marginais, as quais podem ser compreendidas como geradoras de um enriquecimento dissidente e de um bem-estar diver gente em face das lógicas economicistas que predominam no mundo contemporâneo. Neste artigo, vamos estudar determinadas características da arte marginal (outsider art) feitas com objetos do cotidiano, a fim de elaborar algumas orientações metodológicas. A partir destas peculiaridades, abordaremos, igualmente, um tipo de pedagogia popular que permita um trabalho de exploração artística e de emancipação social.

Palavras chave: arte marginal; educação popular; objetos do cotidiano; experimentação; emancipação; riqueza 


\section{INTRODUCCIÓN}

Durante las últimas décadas, la elaboración de mundos artísticos producidos en las orillas del sistema social, económico y político imperante ha constituido un tema de estudios significativo para la investigación social, psicológica y estética. En ese sentido, en este artículo, nos interesa la producción y los procesos creativos del individuo que elabora imágenes visuales desde una marginalidad y bajo una motivación íntima, trabajando en la conformación de un léxico artístico propio, idiosincrático, a partir de un ordenamiento estético y en la creación de un repertorio visual característico. En efecto, la producción visual del artista marginal llama nuestra atención, puesto que pone en juego una emergencia intuitiva, espontánea y radical del imaginario en lo real, es decir, de la realidad de un mundo imaginario en la vida ordinaria.

Respondiendo a una necesidad individual de producción estética, es claro que el arte marginal surge en las orillas exteriores de la sociedad establecida, y se instaura por fuera de los circuitos artísticos institucionales. La creación outsider se desarrolla así en el desconocimiento o en la indiferencia de las enseñanzas académicas y canónicas, establecidas por determinados regímenes artísticos institucionales. Al hablar de arte marginal, nos referimos de esta forma a un arte "en bruto", el cual se constituye al exterior de determinadas estéticas académicas, sean estas premodernas, modernas o contemporáneas.

En su tesis doctoral Procesos creativos en artistas outsider, la investigadora Graciela García Muñoz nos indica:

El término outsider art es posterior al de art brut. En Francia se tenía la costumbre de hacer una distinción bastante estricta entre arte naïf, art brut y arte popular, mientras que en los países anglosajones no existía la noción de "arte bruto" ni se sentía la necesidad de dar continuidad a esos límites. Por este motivo se propuso un concepto equivalente pero más amplio con la denominación outsider art que lanzó el historiador inglés Roger Cardinal en 1972. Se suele decir que en general, el art brut es más "autista", auto-referencial e introvertido, mientras que las obras del arte popular y el arte naïf son más extravertidas y narrativas. En los EE. UU. existe también la acepción folk art para designar las creaciones del arte popular que no son lo suficientemente individuales u originales para ser consideradas outsider art. $(2010,32)$

En ese sentido, la divulgación técnica nos presenta así la denominación outsider art para hablar de la producción visual generada por poblaciones que se encuentran no solo por fuera del mundo del arte instituido como tal, sino igualmente por fuera de los procesos productivos de la sociedad mercante: hablamos de las creaciones visuales realizadas por internos de hospitales mentales, enfermos psiquiátricos, poblaciones carcelarias, infantes y ancianos en estado de aislamiento o soledad.

Ahora bien, más allá de la vinculación entre un tipo de arte y poblaciones cuya vida activa se constituye en los bordes del sistema económico de producción occidental, en este artículo entendemos el arte marginal como una forma de producción artística que presenta un potencial emancipador al generar mundos visuales fecundos y variados, es decir, sistemas estéticos productores de sentido individual y colectivo; sistemas que desligados de un interés por el intercambio económico producen, sin embargo, abundancia y riqueza material e inmaterial. 
En efecto, frente a un mundo donde impera el valor de cambio de objetos y servicios, el arte marginal es productor de patrimonios culturales divergentes. En medio de la masificación de objetos seriales del universo moderno, el arte marginal irradia una acumulación y exuberancia de formas estéticas originales, únicas y hechas a mano.

En ese sentido, la hipótesis que deseamos avanzar es la siguiente: el arte marginal es un fenómeno de producción estética que establece una resistencia crítica al dominio de la interpretación del mundo según la cual la única forma de producir riqueza es generando capital económico. Así pues, en este artículo, analizaremos algunas características del arte marginal como actividad productiva, liberadora y emancipadora frente al sistema económico y social dominante.

En este estudio, haremos referencia especialmente al arte marginal realizado con objetos banales, del mundo cotidiano, especialmente objetos que, habiendo cumplido su rol funcional y perdiendo su valor económico, se les considera de desecho. De esta forma, nos interesa, sobre todo, el arte marginal generado a partir del trabajo de manipulación y reutilización de objetos en desuso, de origen industrial, que hacen parte del espacio doméstico y personal tanto del individuo de los márgenes como de la población en general. Llaman así nuestra atención los objetos domésticos obsoletos que, en una labor creativa, pertinaz y espontánea, son utilizados para un trabajo manual de bricolaje y de collage: yuxtaposición, ensamblaje, combinación y mezcla de formas industriales para crear productos y espacios nuevos y únicos, generadores de valor estético y simbólico. Nos referimos de esta forma a la creación visual realizada en el espacio íntimo y producida por fuera de los determinismos económicos, sociales y académicos dominantes. Se trata así de un tipo de producción visual que permitiría incentivar una práctica artística entendida como instrumento para contribuir a salir de la escasez espiritual, propia del mundo contemporáneo, individualista y mercantil.

Es esta perspectiva una inclinación social dirigida a incentivar nuevas posibilidades de creación de riqueza por fuera de la lectura materialista y economicista del mundo y podemos asociarla al trabajo de ascensión cultural que puede darse por medio de la educación. En ese sentido, el arte marginal podría vincularse a un tipo de educación que surge asimismo en los márgenes de los sistemas institucionalmente establecidos para la pedagogía del arte. En efecto, la educación popular como forma de intervención social desde un modelo crítico de educación artística para todos implica una posibilidad nueva de aprendizaje, la cual resulta singularmente apropiada para un trabajo de construcción social que busca situarse por fuera del sistema institucional y económico dominante.

Así pues, tanto el arte de los márgenes como la educación popular —entendida como educación expandida hacia los márgenes- se presentan como formas culturales en toda apariencia susceptibles de producir conocimiento, emancipación y enriquecimiento social divergente. Entre ambos conceptos - arte marginal y educación popular — surge así una resonancia conceptual disidente y crítica frente al mundo instituido.

De esta forma, nuestra investigación presenta las siguientes preguntas: ¿Podríamos construir un modelo en educación popular que ponga en acción algunas cualidades propias del arte marginal, con el fin de generar procesos de enriquecimiento colectivo, emancipadores y liberadores frente a los sistemas de dominación social? ¿Qué características tendría una educación artística popular que pudiera retomar aspectos propios de la producción artística marginal realizada con objetos de lo cotidiano para producir riqueza cultural? 
Así pues, en este artículo, tenemos como objetivo principal estudiar el trabajo de bricolaje con objetos de lo cotidiano realizado por artistas marginales, para observar si algunas características de este tipo de producciones visuales permiten generar procesos de aprendizaje, que se darían por fuera de los medios, espacios y canales tradicionales de enseñanza, creación y valoración artística.

Nuestra metodología de investigación en este estudio comprende entonces un análisis interpretativo de algunas particularidades de las prácticas de artistas marginales que trabajan con objetos de la vida cotidiana. Este análisis se produce a partir de la mirada del artistainvestigador que indaga y confronta los datos observados con su propia experiencia creativa. Así pues, una observación general de las características del arte marginal y su entendimiento a partir de nuestra propia visión y experiencia de creadores visuales va a permitirnos generar algunas pautas para una pedagogía popular del arte, desde una resistencia cultural a los vectores de dominación económica y estética presentes en las sociedades contemporáneas.

\section{DEL OBJETO DOMÉSTICO COMERCIAL A LA CONSTRUCCIÓN ARTÍSTICA MARGINAL}

Los objetos ordinarios de nuestro mundo doméstico son el resultado de un conjunto de modos de producción y de un intercambio comercial que da cuerpo a un sistema de valores económicos y sociales en el que vivimos. En ese sentido, es pertinente observar que la vocación productiva del objeto comercial —esencialmente funcional- ha evacuado de la esencia del producto su antigua vida histórica y espiritual y la ha eliminado del cuerpo útil de las cosas. Con el proceso económico heredero de la revolución industrial, se ha generado así el sometimiento del objeto ordinario a su reproducción masiva, proceso que hace de las entidades inertes de nuestro entorno inmediato evidencias seriales, domesticadas e inofensivas. El objeto comercial se emplea de esta forma bajo el rigor de unas órdenes y a través de unas instrucciones precisas para su uso, casi siempre predecibles.

Abolida la esclavitud humana en el siglo XIX, para la modernidad resta la esclavitud del objeto: su dominación lograda en parte gracias a la evacuación del espíritu que lo animaba en tiempos míticos. ${ }^{1}$ Así pues, el tiempo moderno ha traído consigo el impulso masificador de las cosas, a partir del cual el primitivo espíritu del objeto ha muerto y dejado solo un cadáver utilitario. Las presencias encarnadas en las formas del entorno han sido reemplazadas por el aplanamiento funcional de lo cotidiano.

Sobre la vida de los objetos modernos, Zygmunt Bauman afirma:

\footnotetext{
Hacer que se muevan objetos inanimados, inmóviles, no tiene en definitiva nada de especial: lo hacemos a diario con esos ensamblajes de hierro y plástico que llamamos coches y trenes. En estos casos, queremos que los artilugios se muevan en la dirección y los tiempos que hemos marcado: queremos que sus movimientos sean normales y predecibles. Pero esta monotonía predecible no da vida a esos objetos, simplemente se les obliga a moverse, de modo parecido a como condenamos otros objetos a permanecer inmóviles, clavándolos en la pared o encerrándolos en un cajón o en un marco. $(2007,12)$
} 
En suma, el mundo premoderno como paisaje sacralizado y movido por las fuerzas animadas del entorno ha sido reemplazado por el universo de lo útil. La marca de fábrica del cosmos moderno es así la proliferación constante de nuevos o renovados productos: asépticos, atractivos y dispuestos a ser comprados para cumplir nuestros requerimientos y órdenes, a través de su manipulación práctica y eficiente. ${ }^{2}$

En su libro El sistema de los objetos, Jean Baudrillard nos indica así:

Hoy en día [...] los objetos dejan traslucir claramente qué es aquello para lo cual sirven. Así, pues, son libres, como objetos de función, es decir, que tienen la libertad de funcionar y (por lo que respecta a los objetos de serie) prácticamente no tienen más que ésta. $(1969,16)$

En ese sentido, el sujeto moderno habita un espacio cotidiano donde la intimidad está constituida de objetos reproducidos y utilitarios. El derecho a la individualidad, como esencia última del liberalismo, paradójicamente hoy en día se manifiesta en el anonimato de la escogencia y de la compra de aquello que es masificado. De esta forma, el sujeto moderno se encuentra estandarizado; no obstante, sus propiedades materiales, como reflejo de su identidad, muestran un collage de gustos.

Baudrillard señala en ese sentido:

El corolario de que todo objeto nos llegue a través de una elección es que, en el fondo, ningún objeto se propone como objeto de serie, sino que todos se nos ofrecen como modelos. El menos importante de los objetos se distinguirá de los demás por una diferencia: color, accesorio, detalle. Esta diferencia será dada siempre como específica. (1969, 160)

Hablamos, pues, de la alienación moderna del individuo serial que, sin embargo, lucha por ser auténtico a través de sus objetos de consumo. Desde un punto de vista religioso, es claro que el triunfo del racionalismo económico sobre el pensamiento mágico ha producido la evacuación de otros modos posibles de entendimiento sobre el entorno humano y sus entidades materiales por fuera del consumo del objeto funcional y comercial. ${ }^{3}$

Ahora bien, frente a la alienación y el empobrecimiento anímico que genera el sistema de producción y consumo de los objetos modernos, un singular ejemplo de resistencia al régimen económico y social imperante puede constituirlo la producción estética del artista marginal. Hacemos referencia aquí a la producción del individuo considerado anormal: la creación que tiende a disminuir la acción de la dominación cultural de la economía por medio de la subversión del orden de los valores mercantiles del objeto y de su espacio, a través de la puesta en juego de la confección de nuevas realidades, disfuncionales en términos utilitarios y principalmente imaginativas y estéticas. 
En su libro La utilidad de lo inútil, Nuccio Ordine nos indica así:

En este brutal contexto, la utilidad de los saberes inútiles se contrapone radicalmente a la utilidad dominante que, en nombre de un exclusivo interés económico, mata de forma progresiva la memoria del pasado, las disciplinas humanísticas, las lenguas clásicas, la enseñanza, la libre investigación, la fantasía, el arte, el pensamiento crítico y el horizonte civil que debería inspirar toda actividad humana. En el universo del utilitarismo, en efecto, un martillo vale más que una sinfonía, un cuchillo más que una poesía, una llave inglesa más que un cuadro: porque es fácil hacerse cargo de la eficacia de un utensilio mientras que resulta cada vez más difícil entender para qué pueden servir la música, la literatura o el arte. $(2013,11-12)$

En este artículo, nos interesa, pues, el trabajo del individuo que siente una pulsión irrefrenable hacia la creación visual y hacia la transformación del mundo que implica, generalmente, en la producción creativa, una fuerza íntima y estética, que no responde a una lógica de los beneficios del mercado.

De esta forma, hablamos de la puesta en escena de una producción subversiva que genera mundos divergentes. En ese sentido, la implicación de la creación visual en un sistema de producción donde en principio desaparece la obligación práctica del objeto hace que el útil, la herramienta, el instrumento, el utensilio y el artefacto pierdan, para el artista marginal, su valor funcional y tengan sentido por su valor estético, a través del potencial transformador del arte.

Un particular modo de hacer artístico a partir de un trabajo con objetos cotidianos constituye una posibilidad de transformación del espacio de lo íntimo. Así pues, de las prácticas del arte marginal queremos subrayar especialmente las actividades de bricolaje realizadas a partir de objetos cotidianos, cuya funcionalidad inicial ha caducado y son recuperados con fines estéticos.

En ese sentido, por ejemplo, una obra marginal como la del artista francés Alfred Marié, nacido en 1951, comprende un trabajo de ensamblajes originales, elaborados con piezas de relojes y antiguas máquinas de escribir, fragmentos de transistores y partes electrónicas de diversos aparatos, pedazos de metal y plástico recuperados de objetos ordinarios, sometidos a procesos de lijado, pegado, pintado, deformación y recubrimiento con pátinas. El resultado escultórico presenta piezas orgánicas, laberínticas y arquitectónicas, micromundos coloridos y repletos de detalles que evocan, en pequeña escala, el carácter recargado de las catedrales góticas (Outsider Art Fair 2017).

Este primer ejemplo de una práctica artística marginal nos muestra cómo el final de la vida útil de los objetos que han cumplido su función utilitaria da paso a una potencialidad de creación estética. Para el artista que trabaja desde los márgenes del sistema, los objetos por utilizar en su labor creativa permiten la transfiguración de lo banal, la mutación de lo usado y la derivación artística generada a partir de lo ordinario. Hablamos, pues, de los productos de un escenario comercial entendidos como materia prima para un determinado trabajo creativo de reutilización y transformación. Trabajo a partir del cual la producción de valores no comerciales, afectivos y culturales aparece por medio de un gesto artístico donde la sistemática de la reproducción técnica e industrializada da paso a prácticas creativas, manuales y experimentales, donde la individualidad del artista se pone en juego. 
En ese sentido, sobre la creación marginal y sus características, Inés Ortega nos indica lo siguiente:

Se trata de obras en las que se condensa lo esencial de la personalidad del creador, lo que en tantas ocasiones supone un reflejo de las particulares, y muchas veces difíciles condiciones vitales de estas personas, cuando no una transcripción formal de sus obsesiones. Esto hace que el contexto en el que se circunscribe el arte outsider, generalmente, sea muy íntimo, y también que se le reconozca un carácter salvífico para quien lo produce, así como una innegable dimensión espiritual, por lo que a veces las obras parecen inspiradas por una fuerza superior que impele a sus creadores a producir de forma compulsiva. $(2014,296)$

Para ilustrar estas últimas ideas, otros ejemplos de prácticas marginales con objetos cotidianos resultan pertinentes: la obra del artista norteamericano sordo y analfabeto James Castle (18991977) es conocida por sus ensamblajes con material de recuperación como cartones y papeles, empaques y envases ordinarios para crear pájaros, trajes y personajes (García Muñoz 2010). Por otra parte, podemos destacar también las naves fantásticas, los barcos y los carros a manera de maquetas realizadas con objetos y materiales reciclados (cartón, madera, metal, utensilios y juguetes diversos) del artista brasileño Arthur Bispo do Rosário (1909-1989), quien sufría de esquizofrenia paranoide. Se destaca, igualmente, del trabajo de este artista las disposiciones y acumulaciones estéticas realizadas con trastos, botellas, zapatillas y peines, entre otros objetos de lo cotidiano, utilizados para sus obras (García Muñoz 2013).

Ahora bien, hemos dicho que según la lógica de la rentabilidad económica la producción de los objetos en nuestras sociedades industrializadas requiere una sistematización y de una técnica eficaz. Al contrario, el arte marginal opera en la creación de configuraciones visuales por medio del descubrimiento y la exploración de técnicas y procedimientos manuales por fuera de la regulación mecánica y sin tener en cuenta una necesidad de rentabilidad económica. El arte marginal implica así la producción de patrimonios personales, la elaboración de fortunas disidentes, cuyo valor se constituye para el individuo a través de la manipulación estética. Así pues, la creación artística de carácter marginal comprende un trabajo que no obedece a la necesidad de intercambio utilitario de bienes y servicios, ya que el ejercicio creativo produce una riqueza en forma de beneficio intelectual y espiritual para el individuo creativo y para su entorno. En último término, este tipo de arte genera un aprendizaje que procura un ascenso cultural y simbólico para la persona que produce creaciones visuales capaces de generar una experiencia singular, interactiva o contemplativa.

La reproducción de objetos codificados bajo la noción de eficiencia se reemplaza, a través de la creación visual, por el juego de articulaciones, manipulaciones y desvíos formales de signos visuales productores de sentido. ${ }^{4}$

El resultado plástico se origina, entonces, trabajando con productos que han perdido su rol funcional y con los cuales se confecciona una nueva realidad estética, singularmente indiferente y resistente a las lógicas capitalistas. La misma realidad puede producir una satisfacción simbólica individual que se encuentra así por fuera del valor normativo del mercado.

En ese sentido, es pertinente mencionar algunos ejemplos que dan cuenta de las ideas anteriores, como la obra del artista alemán Gustav Mesmer (1903-1994), interesado en la elaboración de máquinas voladoras propulsadas por humanos y confeccionadas con bolsas plásticas, sombrillas, bicicletas, maderas y ramas de árboles (García Muñoz 2007). Franco Bellucci (artista italiano nacido 
en 1945), por su parte, trabaja con envases y botellas plásticas, cordones de zapato y calcetines de sus compañeros del asilo, mangueras de jardinería, juguetes de plástico y peluches que anuda y amarra para producir resultados estéticos compactos (Godin 2015).

Sobre los procedimientos creativos empleados por el artista marginal resaltamos las prácticas de collage y de bricolaje con objetos de lo cotidiano. En ese sentido, la creación visual puede producirse de forma mínima, recurriendo a la simple disposición del objeto ordinario como arte (ready-made) o puede constituirse por medio de la modificación, variación y articulación de objetos sometidos a toda clase de manipulaciones personales: ruptura, pegado, trituración, doblaje, insertado, pintado, etc. ${ }^{5}$

A partir de un bricolaje con objetos de lo cotidiano (de cocina, mobiliario, materiales y útiles diversos), la producción visual desde los márgenes da paso a la búsqueda de una singularidad plástica. En esta búsqueda, puede aparecer el encuentro lúcido de una anomalía que se manifiesta en medio del proceso de producción visual. La misma anomalía se presenta como el resultado de una actividad plástica excepcional y da cuenta de una novedad que se expresa por fuera de las asociaciones convencionales y ordinarias, materiales y simbólicas. La confección de una expresión única y su rareza frente al resto de los objetos seriales y comercializables implica así el nacimiento de una entidad singular, de un nuevo objeto o de un espacio estético desconocido que se produce en una historia y en un acontecer personal. La transformación de los productos de uso cotidiano lleva así a una desviación significante del rol utilitario de los objetos y materiales utilizados e impulsa los insumos físicos hacia su vocación de articulación poética, hacia su singularización subjetiva, permitida por el impulso de una creación estética irrepetible.

Nos interesamos, pues, en la plasticidad manifestada en el proceso de transformación de los productos de nuestro mundo cotidiano, a partir de prácticas artísticas donde se pone en juego la fabulación inconsciente que el arte permite. En ese sentido, es importante indicar que, frente al sistema de producción de mercancías seriales, anónimas y sin alma, el trabajo artístico realizado en los márgenes del sistema económico vigente establece con los objetos, no una relación de utilidad, sino más bien un diálogo.

El artista dialoga con los objetos y materiales que utiliza. De esta forma, el individuo creativo deja de ser un usuario de las cosas para dialogar con ellas creativamente. El artista marginal es especialmente apto a este diálogo con los objetos que emplea, entendiendo este diálogo no solo como una metáfora de la transformación creativa, sino como una experiencia que rompe con el espacio de diferenciación entre el objeto y el sujeto.

El artista marginal encuentra así su figura paradigmática en el esquizofrénico aislado o en el niño que tiende a atribuirle vida a aquello que para el sujeto normalizado y adulto, incluso para el artista académico, es solo materia inerte. La tendencia infantil que dota de vida y de intencionalidad a los objetos considerados inanimados se manifiesta igualmente en el anormal que crea formas figurativas personalizadas. ${ }^{6}$ 
En ese sentido, García Muñoz nos indica:

Al dominio del material por parte del artista se le llama técnica. La persona que se acerca al arte de manera intuitiva suele desarrollar una técnica, sí, pero ésta aparece con el tiempo y se basa en esos primeros encuentros con el material, cuando no se persigue dominar nada, sino "escuchar" lo que éste tiene que decir y como mucho entablar un diálogo, el duetto al que alude Dubuffet. Cuando el proceder se repite, el proceso se asienta. En ese momento aparece el hábito. Creadores como Martín Ramírez o Adolf Wölfli comienzan a trabajar sobre papeles sobrantes y una vez se acostumbran a trabajar en ellos, ya no quieren los nuevos. Han encontrado su técnica en un papel no-blanco. (2010, 322)

***

Ahora bien, en la realización artística marginal suele percibirse un carácter rudimentario y primigenio. La exploración primitiva de técnicas por parte del artista marginal se realiza hoy a través de la manipulación de materias y objetos industriales, altamente elaborados desde un punto de vista técnico. Así pues, un trabajo de manipulación y bricolaje se efectúa por parte del artista marginal con objetos y materiales que han sido precedentemente elaborados por medios mecánicos. La anterior constatación nos lleva paradójicamente a una especie de regreso a la prehistoria en la elaboración de los productos por parte del artista outsider. En efecto, la materia prima del arte marginal cuando no es natural es una materia elaborada por la tecnicidad industrial, en este último caso materia que regresa, a través del acto creativo individual, a un estado misterioso y primitivo de lo manipulable y rudimentario, lo que parece implicar una potencialidad mítica nueva. Aquello se observa, por ejemplo, en la producción de figuraciones creadas por el artista outsider con objetos industriales, cuyas formas a menudo recuerdan las del arte mítico de culturas ancestrales no occidentales.

Por otra parte, en la manipulación creativa del arte marginal, se evidencia, además, la importancia de un rito repetitivo, de una disciplina de los sentidos y de un hacer inmerso en la vida cotidiana: cortar, anudar, tallar, rayar, pegar, etc., constituyen una serie de acciones domésticas que permiten un despliegue espacial y un empoderamiento de la vida dado a través de la realización artística.

En ese sentido, un ejemplo de práctica artística producida en el espacio doméstico a través de acciones de bricolaje podemos verlo en el trabajo del artista holandés Bertus Jonkers (1920-2001). De 1989 a 1992, este creador marginal utilizó yeso, pegamento, cartón, arena y materiales diversos para construir una enorme cantidad de edificios que hacían parte de una gran ciudad en miniatura llamada Ciudad de la devoción. En el desarrollo de este proyecto realizado en la casa del artista, la maqueta creció tanto que comenzó a ocupar todo el espacio extendiéndose incluso hasta el jardín (Sutton 2014).

Vemos así en este ejemplo una producción donde la imaginación invade lo real a través del trabajo artístico. Este tipo de invasión de la imaginación en el espacio doméstico se expresa también en la obra de la artista Afia Zecharia de Yemen (1905-2000) que cubrió el interior de su apartamento, incluso el techo y parte del piso, con pintura para automóviles, realizando con ella detallados motivos abstractos, geométricos y psicodélicos, así como figuras de máscaras que se descubren integradas en las formas secuenciales que la pintura presenta sobre las paredes de su residencia (Lavine 2013). 
Por su parte, el artista checo Karel Forman (1929) se ha dedicado a recortar y a pegar en las superficies de su espacio de hábitat miles de imágenes de revistas, periódicos, fotos personales y postales con las que ha ido cubriendo la totalidad de su casa convertida, de ese modo, en un gigantesco collage (Van Es 2014).

Así pues, estos ejemplos nos muestran que para el creador marginal aparece el interés por una reinvención del espacio cotidiano, lo que comporta la indagación por un bienestar material y estético en relación con sus pertenencias. Estas prácticas marginales no están encaminadas a la creación de una propiedad que permita necesariamente el intercambio mercantil, sino más bien se dirigen a la configuración de un mundo fantasmático e identitario.

Por otra parte, una función terapéutica podría desprenderse de las acciones de recuperación, de coleccionismo, de repertorio y de transformación de motivos que, produciendo un conjunto de resonancias individuales, constituyen microcosmos personales, generados en los márgenes de lo social. Así pues, hablamos de mundos constituidos como diseños cerrados de códigos simbólicos, herméticos y, sin embargo, diseños coherentes en lo formal, productores de imágenes enigmáticas y evocativas.

\section{PEDAGOGÍA POPULAR Y ARTE MARGINAL}

La educación popular es una forma de desarrollo educativo actualmente en expansión gracias al trabajo de asociaciones comunitarias que actúan por fuera de los sistemas pedagógicos tradicionales. Este tipo de educación puede entenderse como un espacio donde el conocimiento se construye por medio de la experimentación práctica y de un diálogo generado de manera horizontal entre el educador y los educandos. Según el investigador Agustín Cano, en la educación popular como movimiento político cultural,

pueden encontrarse un conjunto heterogéneo de prácticas, que más allá de sus diferencias (de contenidos, de ámbitos, de estrategias metodológicas), tienen en común una vocación transformadora, un fin liberador organizado en base a la coherencia entre fines y medios, y una opción por los sectores populares. $(2012,25-26)$

Por otra parte, Alfonso Torres señala:

A manera de síntesis, entenderemos la EP como un conjunto de prácticas, actores y discursos en el ámbito de la educación, cuya intención es contribuir a que los diversos segmentos de las clases populares se constituyan en sujetos protagonistas de un cambio profundo de la sociedad. Así, hacer educación popular es reconocer el carácter político de la educación, optar por la transformación de la realidad en búsqueda de una nueva sociedad desde el fortalecimiento de las organizaciones y movimientos gestados por los sectores populares; es trabajar en la creación o desarrollo de las condiciones subjetivas que posibiliten las acciones emancipadoras y de transformación social por parte de estos sujetos populares; es generar alternativas pedagógicas, metodológicas y didácticas coherentes con los postulados anteriores. $(2010,9)$ 
Ahora bien, es importante indicar que el carácter político de la educación popular presenta generalmente un sentido crítico frente a la opresión institucional y cultural. Comprendemos de este modo que la educación popular y la producción en arte marginal son fenómenos culturales que pueden ser entendidos como formas de acción crítica frente a los sistemas de dominación social. Esta perspectiva nos invita a observar así que la educación popular podría generar espacios aptos para la experimentación y la socialización basados en la creación que se produce en los márgenes del sistema social normado e instituido.

Es claro que la visión del artista marginal es una visión transformadora, que nos hace pensar en una pedagogía que incentive una lectura artística divergente de la realidad inmediata, cotidiana y ordinaria para transformarla estéticamente de manera original. La educación popular del arte permitiría así la fundación de un jardín, es decir, el establecimiento de un espacio abierto para la enseñanza y el aprendizaje colectivo, por medio de la transfiguración de lo existente. La idea de un jardín experimental nos brinda así una metáfora de un espacio de transformación social a través del arte, donde los objetos ordinarios del mundo se reconfiguran para revelar lo extraordinario, lo anómalo, la diferencia que produce un gusto estético, una atracción, un poder y un valor no económicos.

En ese sentido, consideramos que, a partir de una educación popular interesada en poner en juego las potencialidades y características del arte marginal, se podría salir de los caminos habituales y esperados en el trabajo de elaboración de imágenes, caminos regulados por una educación sistematizada: manuales de arte, de pintura y escultura, formas tradicionales de representación y de educación del gusto.

Anteriormente, veíamos algunas características de prácticas marginales de bricolaje y de collage, producidas con objetos y espacios de lo cotidiano. Debemos adjuntar una característica más: en toda apariencia, las técnicas de creación del artista outsider no están determinadas por regímenes colectivos y discusivos de carácter tradicional e institucional, por tanto, en el trabajo artístico marginal no aparecen necesariamente unas instrucciones precisas en los procedimientos puestos en marcha para la elaboración de imágenes.

Así pues, el trabajo creativo del artista marginal posee una condición intrínseca antinormativa. En otras palabras, la práctica marginal del arte no se produce siguiendo determinadas reglas preestablecidas por el arte instituido oficialmente. En efecto, para el artista educado, culto, estudiado, las reglas de producción de su trabajo visual están mediadas por un refinamiento estético y cultural que responde a las exigencias de tradiciones particulares y de un medio profesional. Estas exigencias hacen que la producción institucional del arte tienda más sistemáticamente a inscribirse en la búsqueda de determinados resultados canónicos, visuales o conceptuales, requeridos por la experticia profesional.

En ese sentido, al no estar sujeto a la búsqueda de un canon, el artista marginal posee una considerable libertad para la producción material de su trabajo creativo. Así pues, esta libertad le da la oportunidad de abrir espacios de exploración visual en aquello que para el artista educado y profesional posiblemente resultaría inocuo o por costumbre se le revelaría como un gesto trivial. Un juicio aparentemente ilógico, una percepción secundaria, desechada por el artista "educado", es una oportunidad de exploración y puede producir así una salida inesperada y asociaciones múltiples. En ese sentido, la experimentación nueva, individual, particular y propia del artista marginal descubre rutas de acceso a soluciones formales y simbólicas significativas y originales, que se presentan por fuera de los caminos académicos acostumbrados. 
Podría decirse así que el artista marginal no cae en los convencionalismos, no por quererse alejar de ellos, sino frecuentemente por desconocimiento o ignorancia de estos. En ese sentido, la excelencia artística en este tipo de arte depende menos del virtuosismo que de la densidad significante de una expresividad única. Así pues, más que una búsqueda canónica a partir de la inscripción de la práctica artística en determinada tradición, podría pensarse que el arte marginal muestra un gusto por la creación de estéticas divergentes, que permiten la configuración de mundos diversos e individuales, en el mejor de los casos mundos verosímiles y fieles a sí mismos.

De la misma forma, un trabajo creativo ajeno a la evaluación institucional del arte y que compromete una invención intuitiva en la creación de imágenes podría permitir la generación de símbolos que, partiendo de lo individual, resuenen en lo colectivo y puedan, de esta manera, constituir vertientes de sentido estético e identitario, en un mundo cada vez más fragmentado en valores unificadores.

En este punto, nos interesa responder a la pregunta sobre cómo desarrollar una pedagogía que consiga volverse emancipadora a partir de las características del arte marginal que hemos mencionado en este artículo. Para ello, podemos considerar inicialmente que la tendencia a crear formas estéticas, presente en el artista marginal, se encuentra en potencia en todos los integrantes del cuerpo social. A partir de una educación popular, es decir, a partir de una educación para todos, donde prima la experimentación y la comunicación horizontal, se trataría de incentivar la propensión al descubrimiento estético en los individuos interesados en el aprendizaje del arte, para poner en juego ideas que provienen de los procesos creativos del arte de los márgenes. ${ }^{7}$

Así pues, es pertinente conceptualizar unas orientaciones metodológicas generales para una pedagogía popular desarrollada a partir de las potencialidades y características del arte marginal que hemos estudiado. A continuación, estas orientaciones son enunciadas como objetivos por abordar desde talleres y laboratorios artísticos y educativos, centrados en desarrollar prácticas de bricolaje y de collage con productos y objetos cotidianos en desuso. Estos objetivos orientadores son:

1. Incentivar el coleccionismo de objetos inútiles en la vida cotidiana. En ese sentido, el síndrome de Diógenes es el nombre que se le da al coleccionismo considerado enfermizo en la tercera edad por las instituciones psicológicas modernas. García Muñoz nos indica sobre este tema: "Muchos artistas outsider son coleccionistas de objetos desechados o sin valor aparente. Botellas, muñecos, piedras, piñas, conchas... son algunos de los elementos más comunes del imaginario outsider" $(2010,269)$.

El trabajo del artista marginal nos lleva a entender este coleccionismo en su sentido operativo: no como un síntoma de una enfermedad mental, sino como una posibilidad creativa y una tendencia que se puede canalizar para el desarrollo de una actividad artística productora de sentido. La pedagogía popular del arte vendría así a apoyar la acción de recolectar y coleccionar objetos, entendiendo esta acción como una actividad artística en potencia. Baudrillard nos indica que la colección "puede servirnos de modelo: es allí donde triunfa esa empresa apasionada de posesión, donde la prosa cotidiana de los objetos se vuelve poesía, discurso inconsciente y triunfal" $(1969,99)$. 
2. Volver operativos los juegos estéticos rudimentarios en el ámbito del hogar, los gestos de orden subjetivo, de acomodamiento y de organización personal del mobiliario y de los objetos propios, entendiendo los atisbos de órdenes estéticos como procedimientos deliberados que se encauzan hacia la creación estética.

3. Incentivar la articulación y transformación de los objetos en desuso con fines plásticos, por medio del trabajo de bricolaje y de collage.

4. Estimular una praxis de un arte que no esté mediada por la necesidad de innovación, por una evolución de los saberes artísticos o por la inscripción en determinada tradición, sino por manejos manuales y experimentales que nos remontan a la confección rudimentaria, histórica e incluso prehistórica de la manipulación y creación de formas visuales.

5. Favorecer la percepción mágica de la realidad allí donde esta se hace necesaria, es decir, en la producción artística como posibilidad de transformación de la realidad a partir de la imaginación. En ese sentido, se buscaría dejar a un lado la conciencia racional y las barreras que esta produce para encontrar en la creación artística una práctica emancipadora.

6. Incentivar las prácticas manuales que eventualmente permiten la infusión, en un mundo objetual y sin vida, de nuevas entidades que expresen una existencia anímica propia.

7. Promover el autodidactismo como forma de aprendizaje operativa y propia de las prácticas marginales del arte.

Los anteriores objetivos resultan así abiertos a ejercicios diversos de creación por desarrollar a través de una práctica educativa experimental. Por otra parte, la lección que nos ofrecen los artistas de los márgenes consiste en que la experimentación artística de su arte está íntimamente ligada al placer de crear.

Así pues, en una práctica pedagógica realizada a partir de las potencialidades y características del arte marginal, el educador popular buscaría crear un espacio comunitario, que pudiera permitir eliminar los obstáculos intelectuales y culturales que impiden el goce de la creación estética en el público en general. Estos obstáculos podrían darse por la dificultad y frustración experimentada por un gran número de personas al trabajar en formas canónicas de creación, ya que estas formas generalmente demandan habilidades y técnicas de excelencia imitativa, que por su exclusividad impiden en muchos casos la democratización del acto creativo.

Ortega considera así el carácter democrático del arte marginal:

Precisamente por tratarse de una forma de expresión tan necesaria y genuina para la persona que la ejercita, por esa interpretación común de la creación marginal como expresión autónoma e irrenunciable, se ha querido ver en ella una dimensión democrática. El arte estaría al alcance de todo el que sienta la necesidad de expresarse con sinceridad, al margen de su habilidad técnica o sus conocimientos, pues el punto de partida indispensable es el propio sujeto y su motivación interior. El arte deja de ser una opción para convertirse en una vía natural, en la válvula de escape de las personas que, en algún sentido, han sido desposeídas por la sociedad. $(2014,296)$ 
En ese sentido, consideramos así la importancia de incentivar una conciencia participativa y democrática de un arte emancipado de obligaciones preestablecidas, técnicas y canónicas, a través de un aprendizaje en comunidad en torno al acto creativo, lo que, por otra parte, implica aprender a compartir el hacer artístico. El educador popular estaría encargado así de la eliminación de los prejuicios que impiden la emancipación creadora y el goce estético, por medio de una puesta en cuestión del poder de normalización y estandarización que domina al mundo moderno.

De esta forma, la educación popular basada en la experiencia marginal del arte trataría de enfrentar la imposición de todo arte de la costumbre, reemplazando este arte por la creación de lo imprevisto, de aquello que olvida las normas consolidadas en determinadas estéticas, para abrir paso a los procesos empíricos e individuales de exploración y de experimentación estética.

El arte marginal es igualmente un ejemplo referencial del poder de una conciencia imaginativa o de una imaginación consciente, transformadora de lo real. La labor de la educación popular del arte en ese sentido apuntaría a desarrollar en el individuo las herramientas creativas para incidir en lo real, a partir de la imaginación estética y por medio del trabajo plástico que lleva a la transformación de los entornos inmediatos.

Hablamos así de privilegiar en los espacios pedagógicos populares aquello que corresponde a la creación de lugares de resistencia para el imaginario. Se trata, entonces, de superar la experiencia alienante del individuo culturalmente dominado y desarrollar un arte que despliegue una autonomía estética por fuera de la imposición de la cultura regulada y oficial.

Ahora bien, resulta importante en este punto profundizar un poco más en algunas características de la educación popular para afinar el modelo pedagógico que podría ponerse en práctica a partir de las posibilidades y características del arte marginal. Es claro que la educación popular se establece por fuera de las estructuras tradicionales de enseñanza y se encuentra basada en el aprendizaje desarrollado a partir del contexto y del entorno de los individuos. Abierta a todos, en especial a los sectores desfavorecidos de la población, en términos generales, la educación popular comprende una vocación transformadora del espacio individual y colectivo y una intervención en el mundo circundante que resulta afín con el tipo de alteraciones y cambios estéticos del entorno que permite la creación marginal. En ese sentido, incentivar la producción de creaciones visuales no sujetas a las normativas de un cosmos regulado por prácticas artísticas y pedagógicas tradicionales e institucionales permite dar valor a las potencialidades creativas que pueden surgir en los sectores subalternos y oprimidos de la sociedad donde la pedagogía popular encuentra todo su sentido. En su célebre ensayo Pedagogía del oprimido, Freire realiza un nexo entre marginalidad y opresión de la siguiente forma:

Los llamados marginados, que no son otros sino los oprimidos, jamás estuvieron fuera de. Siempre estuvieron dentro de. Dentro de la estructura que los transforma en "seres para otro". Su solución, pues, no está en el hecho de "integrarse", de "incorporarse" a esta estructura que los oprime, sino transformarla para que puedan convertirse en "seres para sí." (1970, 82)

Una educación popular puesta en práctica con las personas y los sectores marginalizados por los cánones económicos, sociales y estéticos imperantes implicaría así una actitud libertaria. En ese sentido, Martín-Barbero nos indica: 
Al deslocalizar los saberes, y trastornar las viejas, pero aún prepotentes jerarquías, el palimpsesto de las múltiples memorias culturales de la gente del común puede libertariamente empoderarse del hipertexto en que se entrecruzan e interactúan lectura y escritura, saberes y haceres, artes y ciencias, pasión estética y acción ciudadana. (2009, 121)

Frente a los sistemas jerárquicos de dominación y ante la depredación de un mundo convertido en objetos de consumo se requiere la resignificación de los espacios y de los productos culturales a partir de la práctica artística, de la vivencia estética que implica una liberación de la alienación creativa para ir hacia una deriva de sensibilización y humanización del entorno y hacia el desarrollo de nuevos valores por fuera de las lógicas del mercado. En ese sentido, siguiendo a Freire, podemos pensar que, a partir de la práctica artística, liberar los objetos y los espacios individuales y colectivos de su domesticación funcional y de su valor mercantil transformándolos estéticamente es igualmente liberar al sujeto de su domesticación. En esta misma perspectiva, incentivar la realización artesanal — propia de la creación marginal—observando que el trabajo manual conduce a una actitud y a una reflexión intelectual es igualmente una manera de reivindicar la creación única frente a un mundo de producción mecánica y serial.

Por otra parte, es claro que el lugar del artista-educador en el ámbito de la pedagogía popular comprendería la instauración y el desarrollo de espacios no formales de experimentación y práctica de la creación visual, para de esa forma generar escenarios participativos que permitan irradiar una transformación cultural a partir del arte. Frente a la crisis actual de la educación formal y académica de las artes, una pedagogía popular de la plástica permitiría a los artistas-docentes operar por fuera de los límites de las instituciones de educación básica, media y profesional, en ámbitos donde se puedan canalizar y desarrollar las capacidades creativas de una ciudadanía que responde al interés estético. En efecto, el carácter dialógico de la educación popular puede ponerse en acción por medio de la conformación de comunidades de aprendizaje y de producción disidente y participativa, es decir, a través de asociaciones de prácticas colectivas de creación y de reflexión abiertas al rol emancipador de la imaginación puesta en obra. Así pues, la tarea de gestión y desarrollo de talleres, laboratorios, seminarios y conferencias en torno al arte a partir de una pedagogía inclusiva implica situar la acción artística y educativa en los contextos donde su rol se hace fundamental para la transformación social.

Ahora bien, reflexionar sobre el rol del educador-artista resulta fundamental para toda creación de un modelo sostenible en una pedagogía popular del arte. La variedad de formas contemporáneas que adquiere el trabajo docente en pedagogías no institucionales nos lleva a encontrar ejemplos de reflexión y de acción para desarrollar una educación popular desde el campo artístico.

En ese sentido, de Paulo Freire podemos revisar la acción de una pedagógica popular constructora de un conocimiento que se desprende directamente de la vivencia cotidiana de las personas, en especial de la vida en los medios desfavorecidos de nuestras sociedades. En su desarrollo teórico y pedagógico en torno a la alfabetización en sectores desfavorecidos del nordeste de Brasil, Freire ha sido especialmente crítico con el carácter vertical de una "educación bancaria", es decir, con la reproducción jerárquica de un conocimiento impartido de profesor a estudiantes de manera vertical, autoritaria o depositaria de un saber. Siguiendo a Freire, generar una relación de comunicación horizontal entre profesor y educandos permite romper con los roles de poder de la educación tradicional, con el fin de construir un conocimiento en común a través de una experiencia colectiva de aprendizaje. 
Es pertinente observar que esta última idea se muestra en especial concordancia con el carácter experiencial y experimental que adquieren las prácticas del arte a partir de los inicios de la modernidad. En esta perspectiva, el conocimiento del educador-artista, quien generalmente ha sido beneficiario de los recursos de la educación académica, puede poner al servicio de la ciudadanía marcos de referencia, teóricos e históricos, para una educación inclusiva y al mismo tiempo poner a dialogar saberes académicos y conocimientos empíricos y prácticos.

De la misma forma, la apertura hacia la libertad creativa que plantea el arte moderno y contemporáneo hace que el profesor-artista pueda canalizar la acción pedagógica hacia la experimentación concebida como una deriva productiva, un viaje y una aventura de creación personal y grupal. En ese sentido, el docente-creador que desarrolla laboratorios y talleres en pedagogía popular puede poner en juego propuestas y retos de exploración que conduzcan a alterar creativamente el entorno inmediato de los participantes de la acción artística y educativa. Despertar y estimular la conciencia sobre las potencialidades de la invención visual como actividad ajena a las lógicas economicistas conduce a pensar en el desarrollo de proyectos que procuren la creación de placer y bienestar simbólico y estético de forma comunitaria. En ese sentido, estudiando los procesos y resultados del arte marginal, la actividad educativa puede iniciar como una invitación a un juego estético que va a permitir vivenciar materiales, productos culturales y acciones activadoras de la memoria, la evocación y la poética. Así pues, modificar la significación de la variedad de objetos y materiales de un entorno cotidiano por medio de su transformación manual resulta un ejercicio abierto a múltiples posibilidades de trabajo y de exploración plástica.

Ahora bien, es claro que la puesta en práctica de un modelo de educación popular en arte depende de cada contexto social donde pueda implicarse una práctica de creación artística emancipadora y su pedagogía. Un ejemplo de diligencia en el tipo de acciones vitales que pueden servirnos de guía para generar un modelo de educación de un arte para todos nos lo ofrece la acción pedagógica del Michel Onfray. Figura clave del pensamiento filosófico en la actualidad francesa, el trabajo de Onfray constituye un importante ejemplo de acción educativa de carácter popular. En efecto, Onfray es creador de la Universidad Popular de Caen, una iniciativa educativa que abre la enseñanza de la filosofía y de otras disciplinas humanistas a las personas del común, a la población en general, a los individuos del mundo cotidiano. Sin limitación de edad o de estudios, sin notas y sin diplomas, este proyecto tiene como principal objetivo generar un aporte para el desarrollo intelectual del individuo que le sirva para enriquecer igualmente su espacio social. La Universidad Popular de Caen constituye así un dispositivo de formación de carácter participativo y democrático para la circulación del conocimiento. A manera de conferencias y de discusiones ofrecidas por profesionales que trabajan voluntariamente, la Universidad Popular de Caen se inscribe en un modelo pedagógico de edificación personal e implica una modalidad de transmisión y de generación de saberes por fuera de la academia tradicional.

Asimismo, el trabajo de Onfray es un vivo ejemplo de cooperación y mutualismo, dos condiciones claves para generar espacios en educación popular. La óptica de Onfray sobre la educación popular igualmente hace énfasis en la posibilidad de transmisión de un conocimiento de calidad, una idea que lo distancia de la concepción de Freire quien, como hemos dicho, cuestiona la unilateralidad de la transmisión del saber, abogando por una horizontalidad comunicativa que permita construir conocimiento entre el profesor y los estudiantes. 
Con estos dos autores y pedagogos, observamos de esta forma dos concepciones divergentes de la pedagogía popular, que hacen evidente la diversidad de posibilidades que el concepto polisémico de educación popular puede encarnar, dependiendo de los contextos y los intereses de cada educador. Así pues, desde nuestra perspectiva, resulta importante mediar entre las dos posturas descritas en busca de una educación popular que permita una horizontalidad en la comunicación y en la exploración de la práctica artística, sin dejar a un lado los saberes que el docente puede aportar para mantener, en los espacios de formación en que trabaja, una calidad de la enseñanza que contribuya a la edificación personal de los participantes de la acción pedagógica.

Por otra parte, para el contexto de la educación en América Latina, la propuesta de Onfray puede resultar particularmente evocativa y atrayente al imaginar la posibilidad de constituir universidades populares con vocación artística, especialmente en los contextos marginales que no gozan de acceso a una educación formal de calidad. La posibilidad de una educación artística por fuera de la academia tradicional, pero invitando a una universalidad del conocimiento, atendería así a la necesidad de contribuir a crear espacios pedagógicos y creativos que permitan a los sectores subalternos de nuestras sociedades sublimar las impulsos destructivos de las violencias que viven o han vivido las poblaciones vulnerables y desfavorecidas en América Latina.

Igualmente, la instauración de un modelo pedagógico popular con una perspectiva de universidad abierta a todos implica necesariamente encontrar apoyos en las instituciones públicas y privadas interesadas en acercar la acción creativa a las poblaciones marginalizadas para hacerlas partícipes de la producción de imaginarios visuales que generen identidad y placer estético. Pensamos igualmente que estos apoyos para iniciativas en educación popular en arte deberían lograrse sin la solicitud de asistencialismos, sino precisamente mostrando la importancia de destinar recursos humanos y económicos para una transformación colectiva por medio de los beneficios que produce la creación visual y su difusión social.

Por otra parte, la producción de relaciones entre cultura académica y experiencias artísticas no institucionalizadas es un campo de investigación que puede igualmente vincularse con las artes comunitarias y participativas. La afinidad entre artes en las que se privilegia la creación de procesos sociales y la educación popular de la plástica es un tema de estudio abierto a profundizaciones teóricas diversas. Desde nuestra perspectiva, hemos mencionado el interés de la construcción de conocimiento en comunidad sin dejar de lado la práctica que conduce a la producción objetual y espacial de carácter perfectible, lo que constituye una característica propia del arte marginal. En ese sentido, los saberes que se elaboran individualmente y luego en colectivo, por medio de una educación popular, conducen a una actividad pedagógica de encuentro. Hemos mencionado que las creaciones del artista marginal tienen como característica el autodidactismo. Nos interesamos especialmente en este último concepto para entenderlo como una actividad de aprendizaje autónomo, basada en la inclinación hacia el descubrimiento y dirigida a una investigación que hoy amplía su campo de recursos, dadas las nuevas modalidades de circulación del conocimiento. El autodidactismo como método de autoformación en una pedagogía popular conduce así al encuentro donde se comparten colectivamente los hallazgos realizados individualmente. A partir de la socialización pedagógica, los aprendizajes autodidactas se entenderían como procesos que no terminan solo en el provecho individual sino que son compartidos por medio del diálogo, en un intercambio y en el marco de una actividad de aprendizaje grupal, lo que implica una apertura 
hacia la comunicación intersubjetiva. Nos referimos así a un proceso pedagógico que surge a partir de un autodidactismo que se discute en comunidad, donde, a través de la creatividad y del diálogo sobre los procesos artísticos, se pone en juego el poder del arte para generar vínculos sociales. En ese sentido, la práctica marginal del arte y su carácter autodidacta son, pues, fenómenos creativos conducentes a una vivencia estética en comunidad que puede generar relaciones de intimidad con el ámbito de un arte relacional articulado a una pedagogía popular en la que se comparten experiencias sensibles.

\section{CONCLUSIONES}

En este artículo, hemos querido señalar un trabajo intelectual y artístico útil para oponernos al empobrecimiento social generado por las lógicas alienantes del comercio y del consumo de objetos industrializados y cotidianos. Hemos conceptualizado así unas orientaciones metodológicas para una educación popular en arte que permita canalizar las potencialidades y características del arte marginal, con el fin de generar prácticas educativas y artísticas que enriquezcan nuestro entorno cultural.

De esta forma, hemos entendido que un florecimiento social y cultural puede generarse acordando una importancia singular al rol de la educación estética. Hacemos referencia así a una apertura pedagógica hacia procesos artísticos que permitan la creación de placer estético, lo que puede redundar en proyectos creativos emancipadores, individuales y colectivos, generados a partir de la experiencia de producción plástica. De esta forma, hemos hecho énfasis en el mejoramiento de la calidad de vida en espacios sociales populares, a partir del goce creativo y a través de la valorización de lo inútil como base para la producción artística de formas y mundos individuales y nuevos. Una apertura hacia la creación y la lectura de la expresión artística y del acto creativo implica, claro está, una experiencia de liberación del sujeto no dispuesto a rendirse a la interpretación materialista del mundo y a las lógicas del mercado como el único sistema que crea riqueza cultural.

Nos referimos así a un arte encargado tanto de contradecir la funcionalidad que da valor a los objetos como de redefinir los criterios de valor de estos. Nuestra tesis ha consistido en indicar que, a través de una transformación plástica de lo cotidiano y de lo inútil, podemos mejorar nuestro entorno, apelando a las potencialidades del arte marginal y al ejercicio de la creación en determinados espacios pedagógicos.

Por otra parte, el desarrollo de relaciones y actividades comunitarias puede desembocar en mundos asociativos y militantes que den importancia a la estética en la cultura y a su producción desde ámbitos no institucionales.

Transformar el mundo a partir de la nada, trabajar sobre una pedagogía que materialmente saca provecho de la abundancia de lo escaso, de los recursos precarios que se encuentran en los espacios y en los objetos desechados o marginales de lo cotidiano, es una tarea que permite un beneficio divergente, en un mundo obsesionado por la rentabilidad económica.

Hablamos así de un enriquecimiento social, simbólico y cultural que contribuye a la elevación de la calidad de vida de los individuos creativos y de sus entornos, por fuera de las lógicas mercantiles y economicistas y a partir de procesos sociales que convocan una educación accesible a todos, especialmente para aquellos que no gozan de los recursos de una educación de élite. 
NOTAS

1 De hecho, las fantasías robóticas de la rebelión de las máquinas tan frecuentes en la ciencia ficción moderna dan cuenta de un miedo original al regreso de un mundo animado que otrora dominaba al hombre.

2 De la abolición de la esclavitud humana se desprende la servidumbre eficaz de los objetos funcionales.

3 En este punto, un nuevo espiritualismo solicita un papel singular en la creación artística. Un papel que resulta siendo de carácter político: volver a infundir un alma única en los objetos se procura una actividad indispensable frente a la cosificación del mundo y la masificación objetual. Así pues, en medio de la vida cotidiana, el impulso creativo es susceptible de ser entendido como un instrumento de infusión anímica en el cuerpo de los objetos, lo que permite entrever espacios mentales constituidos al margen del racionalismo y de las lógicas funcionales del mercado de productos. La creación artística permite pensar así en un proceso de individuación por medio de la creación de imágenes hechas con los objetos que se tienen a la mano. La invención personal aparece en oposición a la alienación utilitaria y la creación artística establece así una apertura a otros mundos posibles frente al universo del rendimiento económico y de la funcionalidad objetual.4 Igualmente, se pide tener en cuenta el credo religioso de los familiares, si se quiere o no que la entrega sea individual o colectiva, etc.

4 En el ámbito de la producción de la imagen, se pueden también buscar nuevos usos a objetos que devienen útiles de creación y que permiten transformar y alterar otros objetos.

5 En el trabajo plástico con los objetos, frecuentemente lo esencial en términos funcionales pasa a ser ornamental y a la vez lo ornamental se hace esencial.

6 Así pues, podríamos decir que en el diálogo creativo entre individuo y forma artística en proceso se lleva a cabo —en un sentido metafórico o real—una infusión anímica en la materia. En ese sentido, la relación entre individuo y objetos manipulables da cuenta de un intercambio: la materia habla, se expresa, los materiales informan y a la vez producen forma. La propia psique dialoga con el cuerpo plástico en constitución, es entonces la materia gris comunicándose con sustancias menos elaboradas o en proceso de elaboración. Así pues, el espíritu del creador, como un demiurgo, infunde su inteligencia al objeto plástico. En esta perspectiva, la creación estética marginal es especialmente susceptible de un trabajo a partir de aquellos productos inanimados e industrializados que, a través de su transformación plástica, adquieren una fuerza o impulso vital nuevo. Vale la pena de esta forma resaltar el interés que presenta un rastro de animismo implicado en la experiencia creativa inmediata, presente en las artes primitivas y generalmente en los productos representativos del artista marginal, lo que no es ajeno a un vitalismo en el hacer.

7 En ese sentido, las prácticas de bricolaje realizadas a partir de productos y objetos cotidianos y de desecho son un ejemplo de procesos que recurren a aquello que tenemos fácilmente a la mano en nuestro entorno inmediato. 


\section{REFERENCIAS}

Baudrillard, Jean. 1969. El sistema de los objetos. Traducido por Francisco González Aramburu. México: Siglo XXI.

Bauman, Zygmunt et al. (2007). Arte, ¿líquido? Traducido por Francisco Ochoa de Michelena. Madrid: Sequitur.

Cano Menoni, José Agustín. 2012. "La metodología de taller en los procesos de educación popular". Revista Latinoamericana de Metodología de las Ciencias Sociales 2 (2): 22-52.

Freire, Paulo. 1970. Pedagogía del oprimido. Traducido por Jorge Mellado. México: Siglo XXI.

García Muñoz, Graciela. "Máquinas para volar". El Hombre Jazmín. Editor. 2 de diciembre de 2007. http:// elhombrejazmin.com/tag/gustav-mesmer/. 28 de enero de 2017.

García Muñoz, Graciela. 2010. "Procesos creativos en artistas outsider". Tesis doctoral, Madrid, Universidad Complutense de Madrid.

García Muñoz, Graciela. “Exposición de James Castle en el Museo Reina Sofía”. El Hombre Jazmín. Editor. 29 de mayo de 2011. http://elhombrejazmin.com/2011/05/exposicion-de-james-castle-en-el-museo-reina-sofia/. 28 de enero de 2017.

García Muñoz, Graciela. "La vuelta al día en cuatro mundos (1/4) Bispo do Rosario". El Hombre Jazmín. Editor. 27 de diciembre de 2013. http://elhombrejazmin.com/2013/12/la-vuelta-al-dia-en-cuatro-mundos-14-bispo-do-rosario/. 28 de enero de 2017.

Godin, Philippe. "Bellucci, I'irrécupérable de l'art brut." La diagonal de l'art, Libération. Editor. 10 de noviembre de 2015. http://diagonaledelart.blogs.liberation.fr/2015/11/10/bellucci-lirrecuperable-de-lart-brut/. 28 de enero de 2017.

Levine, Angela. "Coming in from the Cold - Outsider Art at the Haifa Museum". Midnight East. Editor. 4 de marzo de 2013. http://www.midnighteast.com/mag/?p=24908. 28 de enero de 2017.

Martín-Barbero, Jesús. 2009. "Ciudad educativa: de una sociedad con sistema educativo a una sociedad de saberes compartidos". En Educación expandida, editado por Rubén Díaz y Juan Freire, 103-128. Sevilla: Zemos 98.

Ordine, Nuccio. 2013. La utilidad de lo inútil. Traducido por Jordi Bayod. Barcelona: Acantilado.

Ortega, Inés. 2014. "Nuevas visiones del arte outsider". Arte, Individuo y Sociedad 26 (2): 287-299.

Outsider Art Fair. 2017. "A.C.M.,' acceso el 28 de enero de 2017, http://fr.outsiderartfair.com/artiste/1214

Sutton, Benjamin. “Bertus Jonkers, Sculptor of Mini Metropolises." Hiperallergic. Editor. 18 de diciembre de 2014. http://hyperallergic.com/169762/bertus-jonkers-sculptor-of-mini-metropolises/. 28 de enero de 2017.

Torres, Alfonso. 2010. “Educación popular y producción de conocimiento". La Piragua, Revista Latinoamericana de Educación y Política, 32: 8-25.

Van Es, Henk. "Karel Forman, Collage decorated interior". Outsider Environments Europe. Editor. 6 de abril de 2014. https://outsider-environments.blogspot.com.co/2014/04/karel-forman-collage-decorated-interior.html. 28 de enero de 2017.

\section{Cómo citar este artículo:}

García Camargo, Dimo Leonardo. 2017. “Pedagogía popular a partir de prácticas artísticas marginales realizadas con objetos de lo cotidiano". Cuadernos de Música, Artes Visuales y Artes Escénicas. 12 (2): 125-145. https://doi.org/10.11144/javeriana. mavae12-2.pppp 